To Maega $\mid$ Jurnal Pengabdian Masyarakat

Oktober 2021, Vol.4, No.3, hal, 281-290

$\operatorname{ISSN}(P): 2622-6332 ; \operatorname{ISSN}(E): 2622-6340$

http://www.ojs.unanda.ac.id/index.php/tomaega

\title{
Edukasi Penanaman Bibit Vanili Pada Pekarangan Rumah di Desa Yehembang Kangin
}

\author{
I Gusti Putu Riyan Nugraha ${ }^{1 *}$, Adie Wahyudi Oktavia Gama ${ }^{1}$, Wayan Sutama ${ }^{1}$ \\ ${ }^{1}$ Universitas Pendidikan Nasional \\ *Correspondent Email: adiewahyudi@undiknas.ac.id \\ Article History: \\ Received: 23-08-2021; Received in Revised: 21-09-2021; Accepted: 01-10-2021 \\ DOI: http://dx.doi.org/10.35914/tomaega.v4i3.825
}

\begin{abstract}
Abstrak
Kegiatan pengabdian kepada masyarakat ini dilakukan dalam rangka memberikan edukasi penanaman bibit vanili pada pekarangan rumah di Desa Yehembang Kangin, Tabanan, Bali. Penulis menemukan bahwa masyarakat belum dengan baik memanfaatkan lahan kosong pada pekarangan rumah mereka. Tujuan dari pengabdian masyarakat ini adalah untuk membantu masyarakat dalam memanfaatkan lahan kosong pekarangan rumah mereka dengan menanam tanaman bibit vanili agar masyarakat memiliki kegiatan yang menghasilkan. Metode yang digunakan pada kegiatan ini adalah tahap observasi dan edukasi langsung dengan mengunjungi rumah warga yang memiliki pekarangan luas, maupun edukasi tidak langsung yang dilakukan secara online menggunakan media digital serta tahap evaluasi untuk mengetahui ketercapaian kegiatan. Dengan adanya kegiatan pengabdian ini, masyarakat akan lebih sadar akan keuntungan dalam memanfaatkan lahan pekarangan rumah serta membangun minat mereka dalam menanam bibit vanili.
\end{abstract}

Kata Kunci: pemanfaatan pekarangan rumah, edukasi penanaman vanili, alternatif peningkatan kesejahteraan, pengabdian masyarakat

\begin{abstract}
This community service activity was carried out in order to provide education on planting vanilla seeds in the yard of the house in Yehembang Kangin village, Tabanan, Bali. The author finds that the community has not properly utilized the vacant land in their yards. The purpose of this community service is to assist the community in utilizing the vacant land in their home yards by planting vanilla seeds so that the community has productive activities. The method used in this activity is the direct observation and education phase by visiting the homes of residents who have large yards, as well as indirect education conducted online using digital media and the evaluation phase to determine the achievement of the activity. With this service activity, the community will be more aware of the benefits of utilizing their yards and build their interest in planting vanilla seeds.
\end{abstract}

Key Word: utilization of home yards, education on vanilla planting, alternatives for improving welfare, community services 


\section{Pendahuluan}

Desa Yehembang Kangin merupakan salah satu desa yang berada di Kabupaten Jembrana, Provinsi Bali, yang masyarakatnya sebagian besar bekerja di bidang Pertanian. Kawasan Desa Yehembang Kangin memiliki hamparan sawah yang luas sehingga masyarakat cukup bergantung pada hasil panen sawah. Selain di bidang Pertanian, beberapa masyarakat juga bekerja sebagai pedagang. Desa Yehembang Kangin berada di jalur Denpasar - Gilimanuk yang dilewati banyak pengendara sepeda motor dan mobil dari sekitar Bali yang akan melakukan penyeberangan ke Gilimanuk maupun dari Pulau Jawa yang biasanya akan masuk ke Bali. Terdapat banyak pedagang di sekitar tempat persinggahan tersebut dan selalu ada pelanggan yang membeli makanan kecil atau air untuk bekal saat perjalanan. Kehidupan ekonomi masyarakat sebagian bergantung dari hasil pertanian dan sebagai pedagang pada tempat persinggahan tersebut.

Pandemi COVID-19 telah berdampak luas terhadap kehidupan sosial ekonomi masyarakat, termasuk ketahanan pangan. Di masa Pandemi COVID-19 ini masyarakat merasakan penurunan nilai tukar hasil panen seperti turunnya harga beras dan harga buah, susahnya mengirim hasil produksinya keluar, dan kurangnya minat pembeli (Darwis et al., 2020). Selain petani, dampak ini dirasakan juga oleh pedagang. Pembeli berkurang karena terdapat pembatasan kegiatan dalam masyarakat untuk melakukan kegiatan seperti bepergian, sehingga sedikit orang yang berani untuk keluar rumah. Pembatasan tersebut juga dirasakan oleh pedagang dimana terdapat pengaturan jam buka usaha sehingga berdampak terhadap penjualan. Karena kondisi tersebut banyak masyarakat tidak memiliki kegiatan lain selain berdiam diri di rumah.

Beberapa masyarakat Desa Yehembang Kangin rata-rata memiliki lahan kosong di pekarangan rumah maupun kebun di rumah mereka. Lahan kosong tersebut banyak yang tidak dikelola dengan baik sehingga beberapa rumah masyarakat terlihat kurang memanfaatkan lahan kosong tersebut. Pekarangan rumah yang kosong memiliki banyak potensi untuk mendukung ketahanan rumah tangga (Ashari et al., 2016). Berbagai macam tanaman dapat ditanam untuk mendapatkan hasil yang nantinya dikonsumsi sendiri ataupun dijual guna menambah kesejahteraan keluarga (Dewi \& Widiyawati, 2019) (Suwarno, 2018). Salah satu alternatif tanaman yang dapat ditanam pada pekarangan rumah adalah jenis tanaman vanili. vanili merupakan tanaman yang bisa menghasilkan bubuk vanili yang dapat diolah sebagai pengharum makanan. Keuntungan menanam vanili adalah bisa di budidayakan di lahan yang sempit dan perawatannya cukup mudah. vanili yang ditanam pada pekarangan rumah akan lebih mudah dipantau perkembangannya dan dapat dengan cepat mengetahui dan mengatasi jika terjadi serangan penyakit pada tanaman. vanili dapat menjadi komoditas unggulan jika mendapat penanganan dengan baik pada lahan yang tepat (Riswanto et al., 2020). 
Dengan latar belakang tersebut, maka kegiatan pengabdian kepada masyarakat ini melakukan kegiatan berupa edukasi menanam bibit vanili sebagai alternatif peningkatan ekonomi masyarakat. Kegiatan ini diharapkan membantu masyarakat untuk lebih memahami proses penanaman vanili dengan baik serta mampu memanfaatkan lahan yang kosong dengan menanam bibit vanili. Dimana kegiatan ini nantinya dapat digunakan sebagai alternatif membantu peningkatan kesejahteraan ekonomi masyarakat Desa Yehembang Kangin. Masyarakat diberikan edukasi tentang bagaimana memanfaatkan lahan pekarangan rumah dengan cara menanam bibit vanili. Edukasi dilakukan secara langsung dengan cara datang ke rumah warga yang memiliki lahan kosong maupun secara tidak langsung atau metode online dengan menyebarkan video edukasi penanaman bibit vanili melalui media digital.

\section{Metode}

Kegiatan pengabdian kepada masyarakat ini dilaksanakan dari tanggal 5 Juni 2021 sampai 27 Agustus 2021, bertempat di Desa Yehembang Kangin, Kabupaten Jembrana, Provinsi Bali. Kegiatan ini dilaksanakan sesuai dengan permasalahan yang ada di Desa Yehembang Kangin, dimana terdapat banyak pekarangan rumah yang luas dan tidak dimanfaatkan. Metode yang digunakan dalam pengabdian masyarakat ini terdiri dari tiga tahap, yaitu tahap observasi, edukasi dan evaluasi. Tahap pertama adalah kegiatan yang di laksanakan dengan melakukan observasi ke pengusaha vanili untuk memperoleh pengetahuan tambahan dalam mengembangkan tanaman vanili serta melakukan survei ke rumah warga yang mempunyai pekarangan kosong untuk diberikan edukasi. Tahap kedua adalah dengan cara edukasi penanaman bibit vanili di pekarangan rumah di Desa Yehembang Kangin yang dilaksanakan dengan dua cara yaitu, secara langsung dan secara tidak langsung. Tahap ketiga adalah melakukan evaluasi dan mengukur perubahan yang terjadi pada masyarakat setelah kegiatan pengabdian ini dilakukan. Tahapan metode diatas dapat di uraikan sebagai berikut:

1. Tahap Observasi

Kegiatan pertama yang di lakukan yaitu observasi ke pengusaha vanili dan ke rumah masyarakat. Pelaksanaan observasi dilakukan agar mengetahui informasi lebih lanjut tentang vanili serta mengetahui keadaan masyarakat yang belum dengan baik memanfaatkan lahan kosong pekarangan rumah mereka. Observasi pertama di lakukan ke perkebunan pengusaha vanili yang juga berlokasi di Desa Yehembang Kangin. Selanjutnya dilakukan kegiatan tanya jawab kepada pengusaha vanili yang berkaitan dengan strategi cara menanam vanili yang baik serta cara merawatnya. Pelaku usaha tersebut juga memberikan beberapa bantuan bibit vanili untuk di berikan kepada masyarakat yang tertarik untuk menanamnya dilahan pekarangan rumah mereka. Setelah mendapat informasi mengenai tumbuhan vanili, penulis melakukan observasi kedua dengan datang langsung ke 
rumah masyarakat untuk melihat kondisi lahan yang belum dimanfaatkan dengan baik.

\section{Tahap Edukasi}

Kegiatan selanjutnya adalah memberikan edukasi kepada masyarakat tentang bagaimana memanfaatkan lahan kosong rumah mereka untuk di tanami bibit vanili. Dalam edukasi tersebut, masyarakat akan di beritahu bahan yang di butuhkan untuk menanam vanili, cara menanam bibit vanili, cara perawatan vanili, dan waktu vanili bisa di panen serta rincian harga hasil buah vanili tersebut. Melalui tahap edukasi, penulis melaksanakannya secara langsung yaitu mendatangi rumah masyarakat yang memiliki pekarangan rumah yang luas dan kosong serta edukasi tidak langsung yaitu melalui media digital yang disebarkan kepada masyarakat sekitar. Tahap secara langsung dipilih agar masyarakat lebih mengetahui cara memanfaatkan lahan kosong mereka dengan di tanami vanili serta penulis juga ikut membantu dalam menanam bibit tersebut. Penulis juga memberikan beberapa bibit vanili kepada masyarakat yang telah di titipkan dari pengusaha vanili. Agar edukasi ini dapat di terima secara merata. Edukasi secara tidak langsung dilakukan dengan membuat video tutorial cara menanam bibit vanili yang akan disebarkan melalui aplikasi Whatsapp secara berantai yang nantinya jika masyarakat yang sudah menerima video tersebut bisa meneruskan ke masyarakat yang lainnya.

3. Tahap Evaluasi

Pada tahap evaluasi dilakukan pengukuran tentang bagaimana perkembangan masyarakat sebelum dan sesudah dilakukannya kegiatan pengabdian. Hasil evaluasi ini dirangkum menjadi tabel perkembangan pengabdian. Tahap ini bertujuan agar mengetahui hasil dari pengabdian ke masyarakat serta dampak yang di terima dari edukasi pemanfaatan lahan kosong dengan menanam bibit vanili.

\section{Hasil dan Pembahasan}

Kegiatan kepada masyarakat di laksanakan di Desa Yehembang Kangin, Kabupaten Jembrana, Provinsi Bali mengenai edukasi pemanfaatan lahan kosong dengan menanam bibit vanili dalam upaya meningkatkan kesejahteraan ekonomi masyarakat sekitar. Edukasi ini ditargetkan bagi masyarakat yang berdiam diri dirumah serta yang terdampak akibat adanya Pandemi COVID-19 terutama di bidang pertanian dan bidang perdagangan. Observasi dilakukan dengan mencari informasi langsung pengusaha vanili dan datang kerumah warga melihat pekarangan rumah kosong yang belum di manfaatkan. Dengan adanya bantuan dari pengusaha budidaya vanili dan beberapa masyarakat yang sudah lama terjun di dunia vanili memudahkan penulis dalam mengembangkan ide dan solusi yang penulis kembangkan dalam kegiatan pengabdian ini.

Hasil dari program kerja ini beberapa masyarakat sudah menyadari bahwa mereka tidak memanfaatkan dengan baik lahan kosong pekarangan rumah. Selain menyadari hal tersebut, setelah di edukasi masyarakat tertarik untuk menanam bibit C To Maega / Jurnal Pengabdian Masyarakat. This is an open access article under the CC BY-SA 4.0 license (https://creativecommons.org/licenses/by-sa/4.0/). 
[ 285 ] I Gusti Putu Riyan Nugraha, dkk / To Maega : Jurnal Pengabdian Masyarakat, Vol.4; No.3; Oktober 2021

vanili karena mudah dan bahan yang di butuhkan tidak banyak. Dalam memberikan edukasi, penulis juga memberikan cara menanam vanili dalam bentuk video tutorial cara menanam vanili agar mudah dimengerti dan mudah disebarluaskan. Dalam video tersebut penulis ingin menunjukan bagaimana proses awal cara menanam dan teknis penanaman bibit serta bahan apa saja yang dibutuhkan.

Dalam pelaksanaan Pengabdian di Desa Yehembang Kangin Edukasi ini bertujuan agar masyarakat mengetahui bagaimana cara menanam vanili dan bagaimana cara merawatnya. Edukasi dilakukan secara langsung dengan menerapkan protokol Kesehatan. Agar penulis tidak melakukan edukasi ke banyak masyarakat mengingat Pamdemi COVID-19, penulis membuatkan video tutorial agar mudah di mengerti oleh masyarakat dan mudah disebarluaskan. Hasil dari pengabdian ini di evaluasi dan di rangkum menjadi sebuah tabel agar lebih mudah di mengerti dan dampaknya terlihat

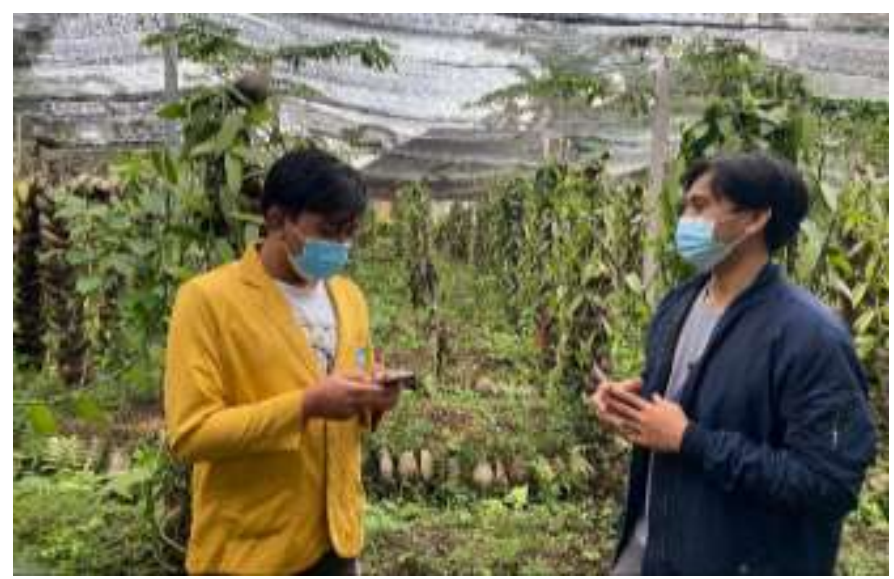

Gambar 1. Kegiatan observasi ke pengusaha vanili

Penulis melakukan observasi dengan datang ke tempat pengusaha vanili untuk mencari informasi seputar cara menanam vanili dan cara merawatnnya yang ditunjukkan pada Gambar 1. Dalam pelaksanaannya, pengusaha merespon dengan baik kegiatan ini dan turut serta juga memberikan bantuan beberapa bibit vanili untuk ditanam pada rumah warga. Hasil dari pendalaman cara menanam vanili ini kemudian dicatat dan dirangkum yang selanjutnya diteruskan kepada masyarakat. 


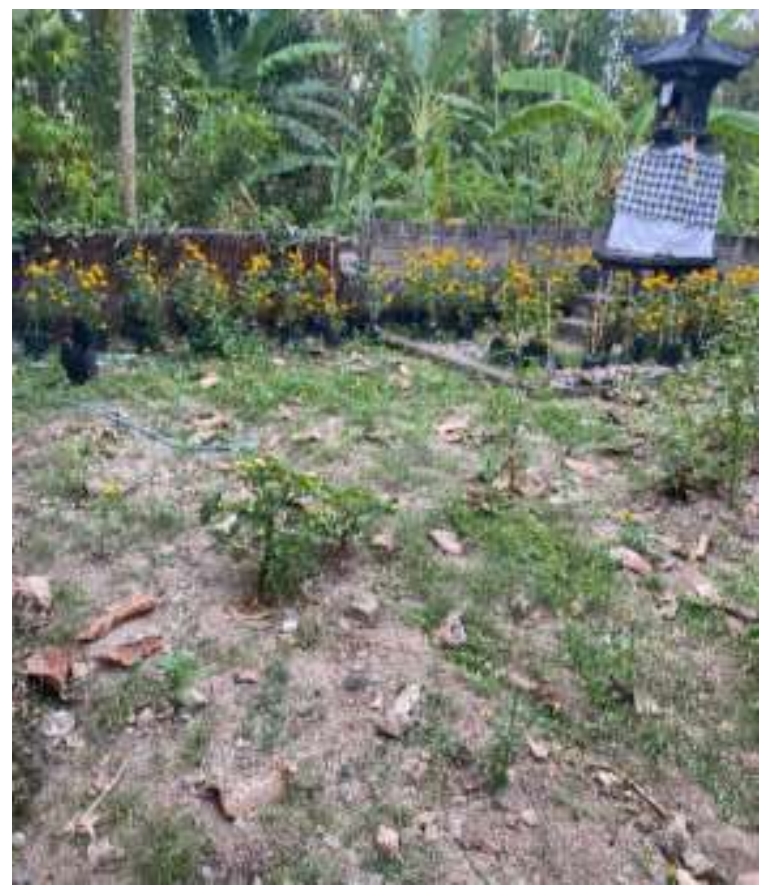

Gambar 2. Observasi melihat lahan pekarangan rumah yang belum di manfaatkan

Pada Gambar 2, dapat dilihat masyarakat belum dengan baik memanfaatkan lahang pekarangan rumah mereka yang luas dan kosong. Pemanfaatan lahan yang tepat akan meningkatkan produktivitas hasil yang dapat menunjang kehidupan ekonomi masyarakat.
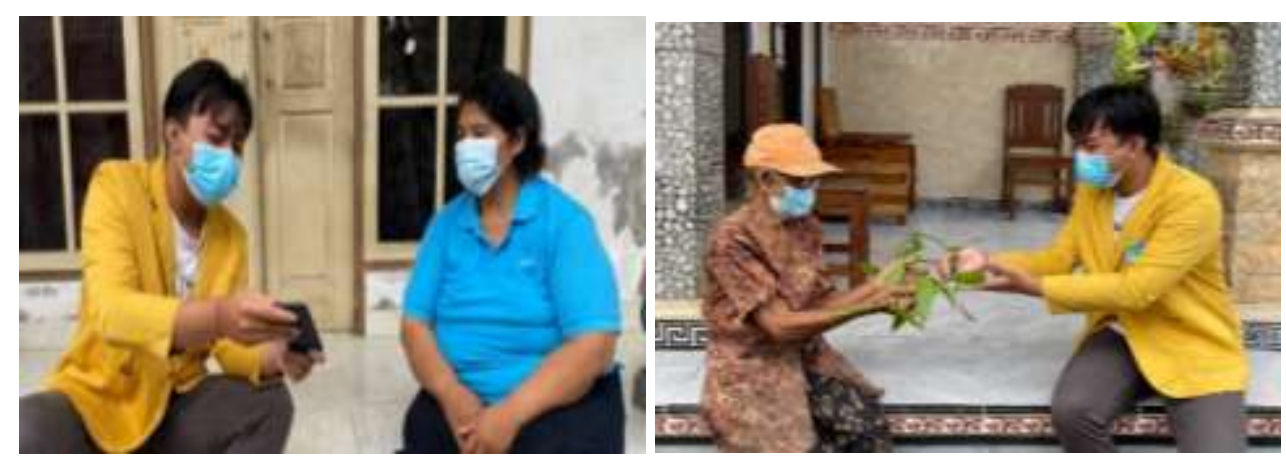

Gambar 3. Memberikan edukasi tanaman vanili kepada masyarakat sekitar

Gambar 3 menunjukkan kegiatan penulis yang melakukan edukasi secara langsung dengan mendatangi rumah masyarakat dan memberikan langsung beberapa bibit vanili yang diberikan oleh pengusaha vanili. Dalam edukasi tersebut, masyarakat diajarkan mengenai bahan yang dibutuhkan untuk menanam, cara menanam bibit, perawatan, dan waktu vanili bisa di panen serta kalkulasi perhitungan pendapatan dari hasil buah vanili tersebut nantinya. Edukasi secara langsung akan lebih meningkatkan pengetahuan masyarakat (Lanamana et al., 2020) karena diberikan dalam bentuk demonstrasi langsung di pekarangan warga. 
[ 287 ] I Gusti Putu Riyan Nugraha, dkk / To Maega : Jurnal Pengabdian Masyarakat, Vol.4; No.3; Oktober 2021

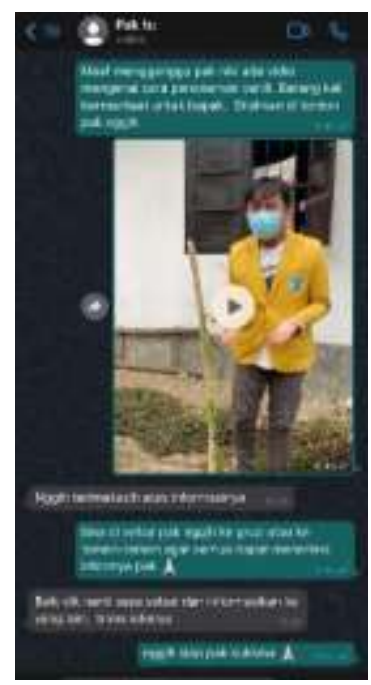

Gambar 4. Edukasi menanam bibit vanili secara Online melalui media WhatsApp

Selain edukasi langsung, penulis juga memberikan edukasi secara tidak langsung via whatsapp yang nantinya akan di sebar juga oleh masyarakat seperti ditunjukkan pada Gambar 4. Masyarakat juga antusias dalam menerima edukasi secara online ini, yang kemudian dilanjutkan dengan meneruskan video edukasi tersebut ke masyarakat sekitar yang ingin menanam bibit vanili dirumahnya.

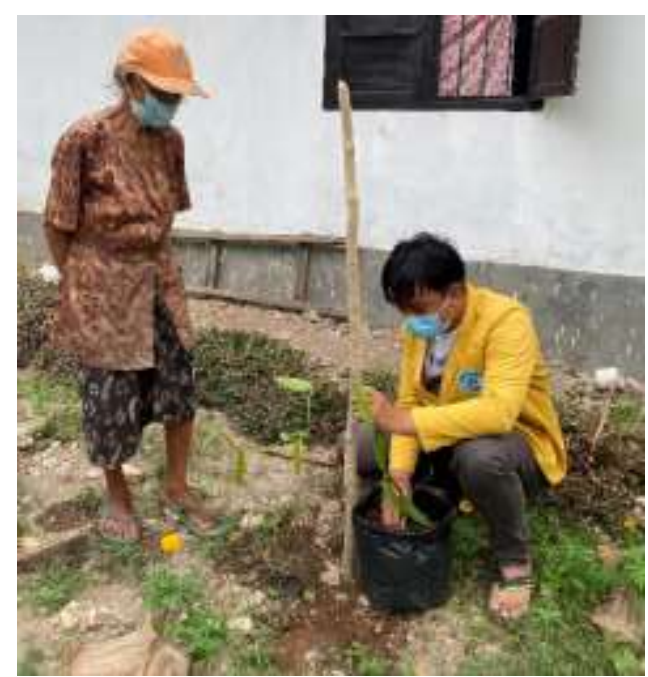

Gambar 5. Membantu masyarakat dalam menanam bibit vanili

Dalam kegiatan pengabdian kepada masyarakat ini, penulis juga ikut membantu dalam proses penanaman bibit vanili di dalam pekarangan rumah masyarakat. Gambar 5 menunjukkan edukasi dengan langsung praktik menanam bibit disalah satu pekarangan rumah warga yang kosong. Terlihat salah satu warga sangat antusias memperhatikan bagaimana cara menanam bibit vanili tersebut. 
[ 288 ] I Gusti Putu Riyan Nugraha, dkk / To Maega : Jurnal Pengabdian Masyarakat, Vol.4; No.3; Oktober 2021

Tabel 1. Evaluasi Perkembangan Kegiatan Pengabdian Masyarakat

\begin{tabular}{|c|l|l|}
\hline NO & Sebelum Pengabdian Masyarakat & \multicolumn{2}{|c|}{ Sesudah Pengabdian Masyarakat } \\
\hline 1 & $\begin{array}{l}\text { Sebelumnya masyarakat belum } \\
\text { dengan baik memanfaatkan lahan } \\
\text { kosong pekarangan rumah }\end{array}$ & $\begin{array}{l}\text { Kini masyarakat menyadari agar lebih } \\
\text { memanfaatkan lahan kosong } \\
\text { pekarangan rumah dengan menanam } \\
\text { bibit vanili }\end{array}$ \\
\hline \multirow{2}{*}{2} & $\begin{array}{l}\text { Sebelumnya masyarakat tidak ada } \\
\text { kegiatan yang bermanfaat di } \\
\text { rumah serta menghasilkan }\end{array}$ & $\begin{array}{l}\text { Sekarang lumayan banyak masyarakat } \\
\text { yang tertarik untuk menanam bibit } \\
\text { vanili dirumah selain mudah dan } \\
\text { bahan yang di butuhkan tidak banyak, } \\
\text { menanam bibit vanili menjadikan } \\
\text { masyarakat mempunyai kegiatan di } \\
\text { rumah dan jika sudah bisa di panen } \\
\text { akan menghasilkan }\end{array}$ \\
\hline 3 & $\begin{array}{l}\text { Masyarakat belum banyak yang } \\
\text { paham terhadap cara menanam } \\
\text { vanili beserta manfaatnya }\end{array}$ & $\begin{array}{l}\text { Masyarakat mengetahui cara dan } \\
\text { potensi penanaman bibit vanili pada } \\
\text { pekarangan rumah tinggal. }\end{array}$ \\
\hline
\end{tabular}

\section{Perubahan dalam pemanfaatan lahan kosong di Desa Yehembang Kangin}

Dalam tabel tersebut dapat di lihat perubahan yang terjadi dalam proses edukasi penanaman bibit vanili di pekarangan rumah yang menjadi pokok pengembangan ide dan solusi yang dilakukan oleh penulis. Sebelumnya masyarakat di Desa Yehembang Kangin belum dengan baik memanfaatkan lahan kosong pekarangan rumah dan belum mempunyai kegiatan bermanfaat yang bisa di lakukan di rumah. Namun dengan adanya ide dan solusi yang penulis berikan, masyarakat sudah sadar bahwa mereka tidak dengan baik memanfaatkan lahan kosong di sekitar rumah mereka dan masyarakat tertarik untuk menanam bibit vanili di lahan tersebut karena cara menanam yang mudah dan bahan yang di butuhkan tidak banyak.

\section{Kesimpulan}

Kegiatan Edukasi pemanfaatan lahan kosong pekarangan rumah dengan menanam bibit vanili di Desa Yehembang Kangin berjalan lancar dan di respon dengan baik oleh masyarakat. Masyarakat yang sebelumnya belum dengan baik memanfaatkan lahan kosong di pekarangan rumah sudah mulai sadar agar lebih memanfaatkan lahan pekarangan rumah mereka dengan menanam bibit vanili karena dalam edukasi tersebut menanam bibit vanili mudah dan tidak membutuhkan bahan yang banyak. Penulis juga menyarankan target agar bibit vanili ini dirawat dengan baik dan lebih menambah lahan untuk menanam bibit vanili hingga nanti buah vanili bisa di panen untuk menambah penghasilan masyarakat jika Pandemi COVID-19 ini belum selesai. Kedepan diharapkan jika 
semua masyarakat sudah memahami dengan baik cara pengembangan tanaman vanili, maka hal ini dapat menjadi salah satu alternatif komoditas utama di Desa Yehembang Kangin untuk dipasarkan. Kemudian kegiatan ini dapat mencetak wirausaha-wirausaha dimulai dari pemanfaatan lahan sekitar dimana Upaya menciptakan wirausaha mandiri berbasis potensi daerah perlu didukung oleh sumberdaya yang siap bersaing (Jumarniati et al., 2020).

\section{Ucapan Terimakasih}

Penulis mengucapkan banyak terima kasih kepada pengusaha vanili yang telah memberikan informasi selengkap-lengkapnya tentang tumbuhan vanili serta mendukung dalam pengabdian masyarakat ini. Terima kasih juga penulis sampaikan kepada LP2M Universitas Pendidikan Nasional atas saran dan bimbingan dalam proses pengabdian, membuat, dan memsubmit artikel ini.

\section{Daftar Pustaka}

Ashari, N., Saptana, N., \& Purwantini, T. B. (2016). Potensi dan Prospek Pemanfaatan Lahan Pekarangan untuk Mendukung Ketahanan Pangan. Forum $\begin{array}{llll}\text { Penelitian Agro } & \text { Ekonomi, } & 30(1), & 13 .\end{array}$ https://doi.org/10.21082/fae.v30n1.2012.13-30

Darwis, V., Maulana, M., \& Rachmawati, R. R. (2020). Dampak pandemi covid-19 terhadap nilai tukar petani dan nilai tukar usaha pertanian. Dampak Pandemi Covid-19: Perspektif Adaptasi Dan Resilensi Ekonomi Pertanian, 83-103. https://pse.litbang.pertanian.go.id/ind/pdffiles/05-BBRC-2020-II-1-4VDS.pdf

Dewi, S. P., \& Widiyawati, I. (2019). Pengenalan Teknologi Budidaya Tanaman Obat sebagai Upaya Pemanfaatan Lahan Pekarangan di Kelurahan Pabuwaran Purwokerto, Jawa Tengah. Jurnal Panrita Abdi, 3(2), 107-111.

Didiharyono, D., Tenrigau, A. M., \& Marsal, M. (2018). Pemanfaatan Sampah Plastik Untuk Dijadikan Bantal Yang Berkualitas Dan Bernilai Ekonomis Di Desa Tolada Kecematan Malangke Kabupaten Luwu Utara. To Maega: Jurnal Pengabdian Masyarakat, 1(1), 8-13.

Intisari, I., \& Rosnina, R. (2019). Pemberdayaan Masyarakat Melalui Pelatihan Berbagai Olahan Jantung Pisang Di Desa Pabbarasseng Kecamatan Bua Kabupaten Luwu. To Maega: Jurnal Pengabdian Masyarakat, 2(2), 58-62.

Ismail, I., \& Syam, A. (2019). Edukasi teknologi hidroponik untuk pemberdayaan lahan pekarangan. Dedikasi, 21(2).

Jumarniati, J., Baharuddin, M. R., \& Hisani, W. (2020). Peluang Wirausaha Mandiri melalui Diversifikasi Olahan Kelapa. To Maega : Jurnal Pengabdian Masyarakat, 3(2), 83. https://doi.org/10.35914/tomaega.v3i2.381

Lanamana, W. B., Fowo, K. Y., Gadi Djou, L. D., \& Pande, Y. (2020). Pelatihan Teknik Budidaya Ubikayu Nuabosi Menggunakan Teknologi Pola Tanam Tumpangsari Dengan Tanaman Legum Di Desa Randotonda Kecamatan Ende Kabupaten Ende. To Maega: Jurnal Pengabdian Masyarakat, 3(2), 92. 
[ 290 ] I Gusti Putu Riyan Nugraha, dkk / To Maega : Jurnal Pengabdian Masyarakat, Vol.4; No.3; Oktober 2021

https://doi.org/10.35914/tomaega.v3i2.376

Oktaviasari, I. N. (2021). Pengorganisasian Masyarakat dalam Meningkatkan

Konsumsi Obat Alami Melalui Pemanfaatan Pekarangan Rumah di Dusun Delik Jombang. Journal of Islamic Community Development, 1(1), 28-35.

Oprasmani, E., Amelia, T., \& Muhartati, E. (2020). Membangun Masyarakat Peduli

Lingkungan Pesisir Melalui Edukasi Kepada Masyarakat Kota Tanjungpinang Terkait Pelestarian Daerah Pesisir. To Maega: Jurnal Pengabdian Masyarakat, 3(2), 66-73.

Riswanto, M., Sataral, M., Yatim, H., \& Katili, H. A. (2020). Kelas Kesesuaian Lahan untuk Pengembangan Tanaman vanili di Kecamatan Balantak Kabupaten Banggai. Cemara, 17(2), 66-74.

Suwarno, E. (2018). Pengembangan Agroforestry Sederhana Di Sekitar Rumah. Dinamisia: Jurnal Pengabdian Kepada Masyarakat, 2(2), 113-120. https://doi.org/10.31849/dinamisia.v2i2.1255

Syam, A., Mahmuddin, M., \& Sudarmi, S. (2020, November). Edukasi Pemanfaatan Lahan Pekarangan Keluarga Rentan Pangan. In Seminar Nasional Pengabdian Kepada Masyarakat (Vol. 1, No. 2). 